\title{
Derivation and validation of a prognostic prediction rule from clinical and stress CMR data characterizes cardiac prognostication in patients with suspected myocardial ischemia
}

\author{
Otavio R Coelho-Filho ${ }^{*}$, François-Pierre Mongeon, Michael Jerosch-Herold, Raymond Y Kwong
}

From 2011 SCMR/Euro CMR Joint Scientific Sessions

Nice, France. 3-6 February 2011

\section{Objectives}

We sought to derive and validate a parsimonious predictive rule incorporating clinical and stress CMR data to characterize major adverse cardiac events (MACE) in patients with suspected ischemia.

\section{Methods/results}

Out of 736 patients referred for assessment of suspected ischemia by vasodilator stress perfusion CMR, 25 (3\%) were excluded due to images of insufficient quality. The remaining 711 patients (297 females, mean age $56 \pm 15$ years) were followed for cardiac events (MACE) that occurred within the first 3 years after CMR (100\% complete follow-up; median of 21.4 months, range 2.5 months to 8.2 years). We randomized patients in this clinical cohort 1:1 into a training set $\left(\mathrm{SET}_{\text {Training, }}\right.$ $\mathrm{n}=356)$ and a testing set $\left(\mathrm{SET}_{\text {Testing, }} \mathrm{n}=355\right)$. Forty-six (6.5\%) patients experienced MACE: 24 (7\%) in the SETTraining and $22(6 \%)$ in the $\mathrm{SET}_{\text {Testing. A parsimonious }}$ prediction rule was built by stepwise regression in the $\mathrm{SET}_{\text {Training, }}$, considering all clinical, ECG, and CMR parameters using $\mathrm{P}<0.05$ for both entry and stay. History of PCI, wall motion abnormality at rest, non-sinus rhythm, and CMR myocardial ischemia score (ISCHSCORE) formed the prediction rule (Table-1). This prediction rule was validated in the $\mathrm{SET}_{\text {Testing }}$ divided into 3 progressive categories based on their ascending predicted probabilities of MACE (low: 1.5 to $10 \%$ and high: $>10 \%$ ). The utility of the model was first determined by comparing the predicted and observed numbers of $\mathrm{MACE}$ in each risk category in the $\mathrm{SET}_{\text {Testing }}$ (Figure-1).

Brigham and Women's, Boston, MA, USA
Table 1 Best overall Model for MACE (SET TRAINING, $_{n=356 \text {, }}$ MACE at 3 years $=23$

\begin{tabular}{llllll}
\hline Variable & Estimate & $\mathbf{L R}_{\mathbf{x}}{ }^{2}$ & OR & P-Value & Final Model \\
\hline ISCH-SCORE, per unit & 0.2104 & 46.3 & 1.234 & $<0.0001$ & $\mathbf{L R}_{\mathbf{x}}{ }^{2}=\mathbf{4 9 . 9}$ \\
Wall Motion Rest & 1.6838 & 15.7 & 5.386 & $<0.0001$ & $\mathbf{A U C}=\mathbf{8 3} \%$ \\
Non sinus rhythm & 1.4101 & 5.3 & 4.096 & 0.02 & \\
Hx PCI & 0.9691 & 4.7 & 2.635 & 0.04 & \\
\hline
\end{tabular}

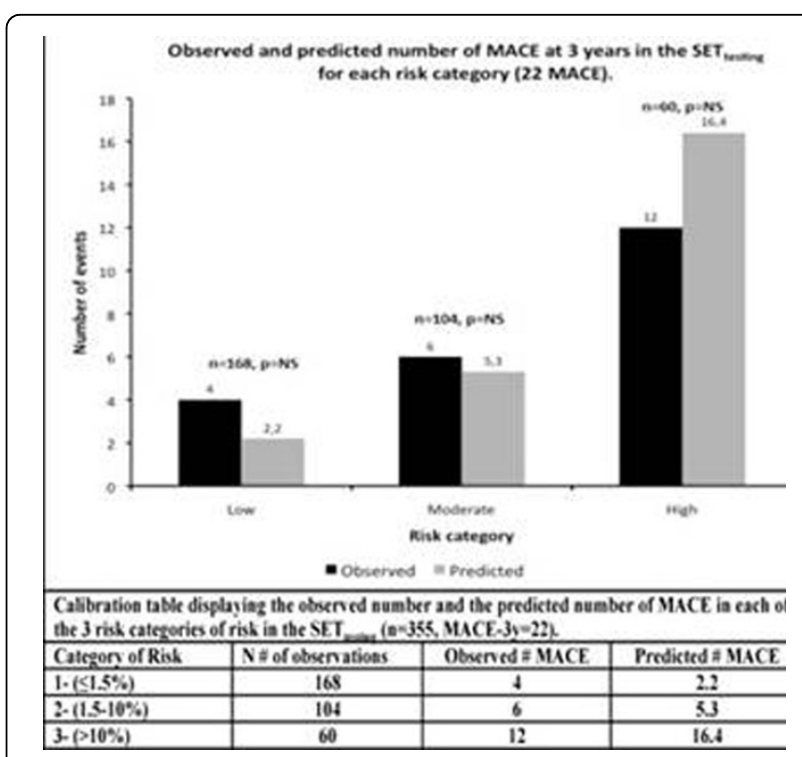

Figure 1 Calibration tables displaying the observed number and the predicted number of MACE in each of the 3 risk categories of risk in the SETtesting ( $n=365$, MACE-3y=22). 


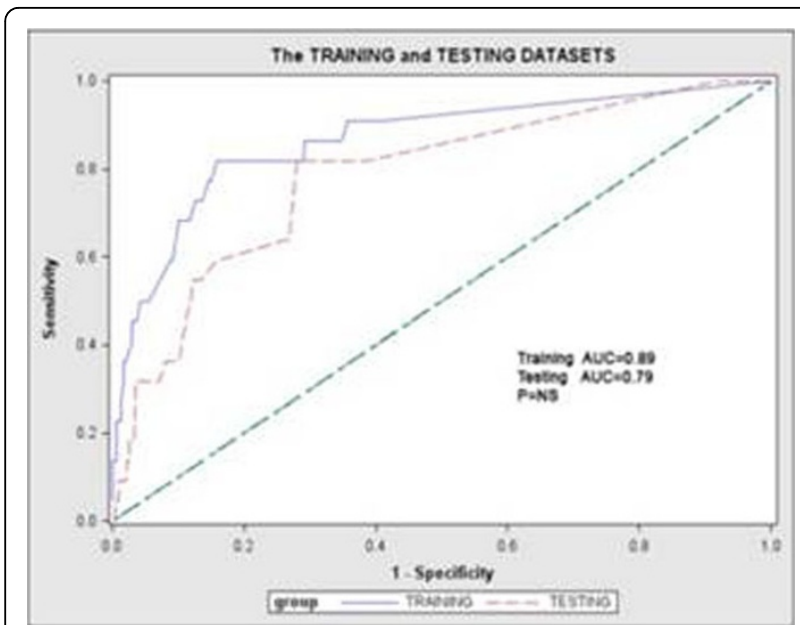

Figure 2 ROC curves of the prediction models derived from the SETtraining (blue line, $A \cup C=86 \%$ and applied to $\mathrm{SET}_{\text {testing }}$ (red line, $A \cup C=79 \%$.

Table 2 Bootstrap International Validation for the Prediction Rule: Based on 400 Simulations

\begin{tabular}{llll}
\hline & Mean & Minimum & Maximum \\
\hline Meal Model AUC & $82.4 \% \pm 3.4$ & $70 \%$ & $93 \%$ \\
Model's Optimism & $7 \% \pm 3.6$ & $-11 \%$ & $12 \%$ \\
\hline
\end{tabular}

We then performed ROC analyses, in either patient set and both sets combined, to determine how well the range of probabilities by the prediction rule can determine MACE occurence. MACE prediction was excellent in $\mathrm{SET}_{\text {Training, }}, \mathrm{SET}_{\text {Testing, }}$, and both sets combined (AUC $83 \%, 86 \%$, and $79 \%, \mathrm{P}=\mathrm{NS}$, figure- 2 ).

In addition, we performed an internal validation of the same prediction rule using 400 bootstrap simulations. Each bootstrap sample was the same size as the original derivation sample, but patients were drawn randomly with replacement from the sample. By bootstrap simulation the prediction rule's estimated optimism was very low $(8 \% \pm 3)$ and mean AUC of the prediction rule was 82.4\% (95\%CI: 70\%-93\%) reinforcing its validity and utility (table-2).

\section{Conclusion}

We derived and validated a prediction rule for MACE using clinical and ISCH-SCORE for patients with suspected myocardial ischemia. ISCH-SCORE provided strong and major prognostic utility in this prediction rule.
Published: 2 February 2011

doi:10.1186/1532-429X-13-S1-O4

Cite this article as: Coelho-Filho et al: Derivation and validation of a prognostic prediction rule from clinical and stress CMR data characterizes cardiac prognostication in patients with suspected myocardial ischemia. Journal of Cardiovascular Magnetic Resonance 2011 13(Suppl 1):O4
Submit your next manuscript to BioMed Central and take full advantage of:

- Convenient online submission

- Thorough peer review

- No space constraints or color figure charges

- Immediate publication on acceptance

- Inclusion in PubMed, CAS, Scopus and Google Scholar

- Research which is freely available for redistribution

Submit your manuscript at www.biomedcentral.com/submit 